\title{
Surgical treatment of carcinoma of the oesophagus
}

\author{
JF DARK, H MOUSALLI, R VAUGHAN
}

From Wythenshawe Hospital, Manchester

ABSTRACT Seven hundred and seventy-two patients suffering from carcinoma of the oesophagus and upper stomach were seen by two surgeons at the Manchester Regional Cardiothoracic Centre over a 15-year period. Five hundred and thirty-one patients had an operation, and of these, 449 had a resection. Throughout the period under review, the policy was to resect the primary tumour whenever possible. No emphasis was placed on extensive preoperative parenteral feeding. Adequate rather than radical resection was the aim of the surgery, but even if a curative operation was not possible, the primary was removed if at all possible. Gastric drainage in the immediate postoperative period by nasogastric tube or pyloroplasty was never used. A new classification of high or low tumours according to the level seen at oesophagoscopy is suggested; in 30 cases designated as "high", a planned resection was carried out using a bilateral thoracotomy, a method not previously described. The overall operative mortality was $9.2 \%$. Of those having a resection it was $7 \cdot 6 \%$, and there were only three deaths in the last 120 resections. The predicted actuarial survival in this series of resections was $18 \%$ at five years and $12 \%$ at 10 years.

The history of the surgical treatment of cancer of the oesophagus and upper stomach is closely related to developments in anaesthesia and the management of a major thoracotomy. It was not until 1933 that the first successful oesophagectomy with reconstruction within the chest was reported by Oshawa, ${ }^{1}$ and in Britain, the first successful transthoracic resection and reconstruction was reported by Thompson ${ }^{2}$ in 1945.

In a recent review of 122 published papers considering surgery for malignant oesophageal disease, the mean hospital mortality after resections was extremely high (29\%). ${ }^{3}$ Twelve per cent of those having a resection lived for five years but only $4 \%$ of those presenting were found to live that long. If these figures were to apply at the present time to this type of surgery in a modern specialist unit, it would be necessary to consider alternative therapy.

There are 50 new cases of oesophageal cancer per million population per year in England and Wales, ${ }^{4}$ and the disease affects older people, many of whom are seriously weakened by undernourishment and degenerative diseases. The main symptom is dysphagia, which may have reached the stage of inability to swallow saliva by the time the patient presents for treatment. Relief can only be provided fully and

Address for reprint requests: Mr JF Dark, Wythenshawe Hospital, Southmoor Road, Manchester M23 9LT. quickly by successful resection of the lesion and alimentary reconstruction.

Seven hundred and seventy-two patients were seen and treated by two surgeons in the Manchester Regional Cardiothoracic Surgical Unit during the fifteen and a half year period from January 1964 to mid 1979. The approach in this series has been directed at successful and complete relief of obstruction in as many instances as possible. Simplicity has been the guiding principle in pre- and postoperative management and in the nature of the operation. All the patients who survived iresection except one were followed up after leaving hospital, and although the final outcome is not known for certain in 26 patients, in 23 of them there is good presumptive evidence that they have died.

\section{Patients and methods}

There were 501 men and 271 women but in the oldest group the numbers of each sex were approximately equal. The average age was 64.5 years, the youngest being 36 and the oldest 92 . The oldest patient having a resection was 87 and the average for the resection group was also 64.5 years.

Patients for surgery with a view to resection were divided into two groups-those where the top of the tumour as seen through the oesophagoscope was below $30 \mathrm{~cm}$ were categorised as being in a low group 
Table 1 Case distribution according to site

\begin{tabular}{lcc}
\hline Patients & $30 \mathrm{~cm}$ and above & Below $30 \mathrm{~cm}$ \\
\hline Non-operated cases & 93 & 148 \\
Explored and inoperable & 13 & 69 \\
Resection performed & 52 & 397 \\
Totals & 158 & 614 \\
\hline
\end{tabular}

and those where the tumour was at $30 \mathrm{~cm}$ or above were regarded as being in a high group. The low group included carcinomas of the cardiac end of the stomach, and there were 466 patients in this category. The case distribution according to the site is shown in table 1.

Histologically there were $86 \%$ squamous cell carcinomas in the upper group and $37 \%$ in the lower group. Five per cent in each group were anaplastic and the rest were adenocarcinomas with the exception of one leiomyosarcoma in the lower group. Apart from radiographic studies, each patient was submitted to oesophagoscopy and bronchoscopy. Two hundred and forty-one were considered unsuitable for major surgical treatment because of clear evidence of widespread distant metastases or extensive involvement of important mediastinal structures. Specifically, invasion of a bronchus or the trachea, a vertbral body, or the left recurrent laryngeal nerve was taken as evidence of inoperability. Some patients were unfit for major surgery because of very advanced age or serious pulmonary or cardiovascular disease.

In all potentially operable patients in the lower group the primary approach was through a left lower thoracotomy and in the patients in the high group (65 patients) the approach was either through a right thoracotomy as advocated by Belsey, ${ }^{5}$ or as a deliberate policy, the approach was first through the left lower chest and then at the same session through the right upper chest.

\section{Surgical considerations}

\section{PREOPERATIVE PREPARATION}

It has not been our practice to take any special measures to improve the nutritional state of the patients, apart from dilatation of the tumour, whenever possible, at the diagnostic oesophagoscopy and the correction of serious anaemia or dehydration. The mean preoperative stay in hospital (apart from the admission for diagnosis) for the whole series was $1 \cdot 5$ days.

\section{OPERATIVE TECHNIQUES}

A double lumen endotracheal tube usually of the Robertshaw variety was used in all cases. Where a left thoracotomy was the approach of choice it was made through the bed of the unresected left eighth rib, not extending beyond the costal margin. In eight cases, however, where the operation was oesophagogastrectomy with a Roux-en-y reconstruction and in one where colon replacement was used, the incision was extended across the costal margin obliquely towards the umbilicus.

The abdomen was entered through an incision in the left half of the diaphragm close to its chest wall attachment, so as to minimise injury to the branches of the left phrenic nerve. Although the mobilisation of the lower oesophagus was done en bloc, taking away the adjacent glands and in nearly all cases removing part of the mediastinal pleura and thus opening the right pleural space, no attempt was made to carry out the sort of radical excision described by Allison and Borrie, ${ }^{6}$ and only in five cases was it found necessary to remove the spleen with part of the pancreas to effect a clearance of the palpable tumour. The method of reconstruction was to fashion a tube from the lower half of the greater curvature of the stomach, to close it completely, and make an end-to-side anastomosis between the cut oesophagus and the front of the tube by an interrupted two layer method using either linen thread or Dexon.

There were 22 high tumours ( $30 \mathrm{~cm}$ and above) where the approach was by a right thoracotomy as described by Belsey. ${ }^{5}$ In 30 cases the stomach was freed through a left lower thoracotomy and incision in the diaphragm and it was then brought up through the hiatus and left in the lower part of the pleural cavity. The wound was closed and the patient was then turned on to his left side and the stomach was anastomosed to the cut oesophagus high in the right hemithorax through a right fifth rib thoracotomy.

\section{POSTOPERATIVE MANAGEMENT}

This has been simple in all cases. A nasogastric tube was never left in position but the patients were given nothing by mouth until bowel sounds were clearly heard, usually after three to five days. During this time intravenous fluid and electrolyte replacement was as simple as possible, and in most cases consisted of three litres per day of $5 \%$ Dextrose in $0 \cdot 18 \%$ sodium chloride for the average adult.

Feeding with water was started when bowel sounds were heard. Subsequently free fluids of all kinds were given, and after 10 days the patients were allowed a light diet.

All patients were put in the sitting position very early after recovery from anaesthesia. Vigorous postural drainage was avoided to reduce the chance of aspiration of gastric contents. Early walking was encouraged even when the intravenous transfusion was still in place and all the patients were given 
Table 2 Operative deaths of resection patients

\begin{tabular}{lccl}
\hline & Resections & Deaths & $\%$ Mortality \\
\hline $30 \mathrm{~cm}$ or above & 52 & 4 & 7.9 \\
Below $30 \mathrm{~cm}$ & 397 & 30 & 7.5 \\
Total & 449 & 34 & 7.6 \\
\hline
\end{tabular}

Table 3 Causes of operative deaths in resected patients

\begin{tabular}{lcc}
\hline Cause & Number & $\%$ \\
\hline Respiratory failure & 11 & $2 \cdot 45$ \\
Cardiac failure & 8 & $1 \cdot 78$ \\
Anastomotic leak & 4 & $0 \cdot 89$ \\
Pulmonary embolism & 3 & $0 \cdot 66$ \\
Cerebrovascular accident & 2 & $0 \cdot 40$ \\
Enterocolitis & 1 & $0 \cdot 20$ \\
Gangrene & 1 & $0 \cdot 20$ \\
Ruptured aneurysm & 1 & $0 \cdot 20$ \\
Renal failure & 1 & $0 \cdot 20$ \\
Peritonitis & 1 & $0 \cdot 20$ \\
Diabetes & 1 & $0 \cdot 20$ \\
Total & 34 & $7 \cdot 60$ \\
\hline
\end{tabular}

Table 4 Early postoperative morbidity

\begin{tabular}{lrrl}
\hline Complaint & Number & $\%$ & Outcome \\
\hline Diarrhoea & 46 & $10 \cdot 20$ & 1 died enterocolitis \\
Sputum retention & 32 & $7 \cdot 60$ & 10 died \\
Anastomotic leak & 8 & $1 \cdot 78$ & 4 died \\
Wound resuture & 4 & 0.89 & 2 associated with \\
& & & anastomotic leaks \\
Empyema & 1 & $0 \cdot 20$ & \\
Subphrenic abscess & 1 & $0 \cdot 20$ & \\
Large bowel herniation & 1 & $0 \cdot 20$ & \\
Haematemesis & 1 & $0 \cdot 20$ & \\
\hline
\end{tabular}

Table 5 Major late morbidity

\begin{tabular}{lc}
\hline & Number \\
\hline Inadequate gastric emptying requiring pyloroplasty & 6 \\
Benign anastomotic stricture requiring dilatation & 19 \\
Malignant anastomotic stricture & 26 \\
\hline
\end{tabular}

prophylactic antibiotics, usually one of the penicillins. In the last three years all patients over 40 years have had subcutaneous heparin 5000 units eight hourly for five days.

\section{Results}

All patients who had a resection and who died before leaving hospital after the operation were recorded as operative deaths and they are listed in table 2. The causes of death are shown in table 3. The early postoperative morbidity is shown in table 4 and major late morbidity in table 5.

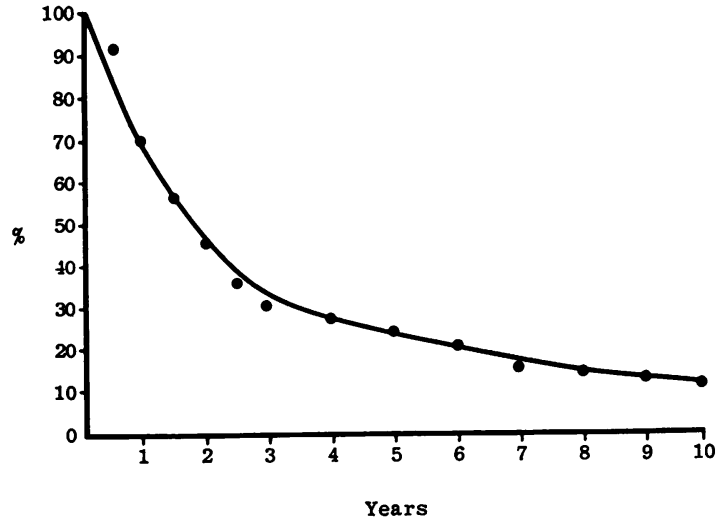

Fig 1 Actuarial predicted survival curve 1964-79. Tumours above $30 \mathrm{~cm}$ (52 patients).

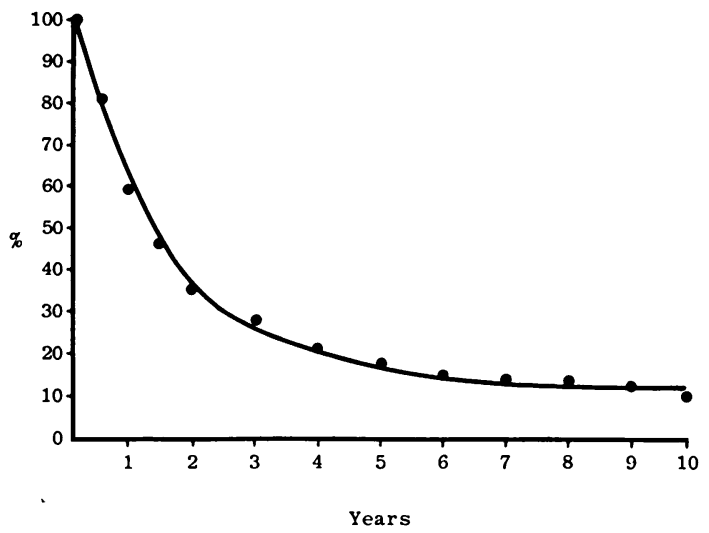

Fig 2 Actuarial predicted survival curve 1964-79.

Tumours below $30 \mathrm{~cm}$ (397 patients).

At the present time, of the 449 patients who had a resection there is a total of 96 survivors. The minimum follow-up is nine months and the maximum is 16 years. Long-term survival in this series is best expressed as an actuarial prediction curve ${ }^{7}$ and figs 1 and 2 show the curves in respect of the upper group and the lower group respectively. The operative mortality was included in making the prediction.

Of the patients who had an exploratory operation, 82 were found unsuitable for resection. Fifty-three of them had insertion of a tube through the obstruction into the stomach and 29 had no effective treatment. The mortality of the intubated patients was high, as $13(24 \%)$ died without leaving hospital.

\section{Discussion}

It has been the custom to divide the tumours according to site into upper third (above the aortic arch), middle third (between the aortic arch and the 
inferior pulmonary vein), and lower third (below the inferior pulmonary vein). ${ }^{89}$

Accurate separation in this way is difficult radiologically and oesophagoscopy gives an imperfect determination of submucosal spread of disease. The latter has been stressed as the most important pathological consideration by McKeown, ${ }^{10}$ Jackson et al, ${ }^{11}$ Miller $^{12}$ and others.

It is considered, however, that an estimation of the distance from the upper gum to the top of the tumour, as seen through the oesophagoscope, offers a useful rule of thumb in planning the surgical approach, and it is suggested that there should be two broad categories-namely, the low group where the top of the tumour is below $30 \mathrm{~cm}$ and the high group where the top of the tumour is at $30 \mathrm{~cm}$ or above. On this basis, all the tumours in the low group might reasonably be expected to be removable through a left lower thoracotomy. Those tumours seen at $30 \mathrm{~cm}$ or above have been approached through either a right thoracotomy as described by Belsey, ${ }^{5}$ or through bilateral thoracotomies at the same operation. An extensive review of the literature has not revealed any previous description of this method, but it has been used by Wingfield (personal communication). It is put forward as an alternative which provides excellent exposure at all points. It allows early discovery of inoperability in either the chest or the abdomen and it has been carried out

Table 6 Operative mortality rates for resection

\begin{tabular}{|c|c|c|}
\hline & Resections & $\begin{array}{l}\text { Operative } \\
\text { mortality } \%\end{array}$ \\
\hline Miller $^{12} 1961$ & 171 & 27 \\
\hline Collis J ${ }^{17} 1971$ & 400 & 26 \\
\hline Belsey $^{5} 1974$ & $\begin{array}{l}140 \text { (middle third } \\
\text { tumours only) }\end{array}$ & 28 \\
\hline McKeown 1972 & 253 & $12 \cdot 2$ \\
\hline Leverment $^{18} 1974$ & 381 & 26 \\
\hline Akiyama $^{14} 1976$ & 140 & $1 \cdot 4$ \\
\hline McKeown $^{13} 1978$ & 372 & $9 \cdot 6$ \\
\hline Jackson J11 1979 & 216 & 18 \\
\hline Schuchmann ${ }^{21}$ & 46 & $21 \cdot 7$ \\
\hline Present series & 448 & $7 \cdot 7$ \\
\hline
\end{tabular}

with a low operative mortality (three deaths in 30 operations $(10 \%))$.

In any large series the results and mortality may only reflect the method of patient selection. Some authors do not make clear their method of selection and McKeown, ${ }^{13}$ for example, reports 403 patients explored, but does not indicate how many were not offered an operation. Akiyama et al ${ }^{14}$ describe 270 patients of whom 140 had a resection, but the total explored is not stated. For these reasons table 5 contains several gaps. The overall operative mortality of the present series (number of hospital deaths related to the number having an exploratory operation) is $9.1 \%$ (49 out of 537), similar to the $9.6 \%$ reported by McKeown ${ }^{15}$ but not as good as that reported by Akiyama et al $^{14}$ and Nakayama. ${ }^{16}$

The operative mortality in the present series for resected cases compares favourably with that of other series as shown in table 6.

The annual number of resections performed has slowly increased over the years and the operative mortality has decreased recently. This trend of improvement accords with the experience of Collis. ${ }^{17}$ Leverment and Milne, ${ }^{18}$ and McKeown ${ }^{13}$ and contrasts with the statement of Jackson et al ${ }^{11}$ that in their series there was no improvement in mortality over the 15-year review period.

The survival prediction curve in the present series reveals that at five years, $26 \%$ of the high group having resections should be alive, and at 10 years survival is reduced to $12.5 \%$ (fig 1 ). In the low group the figures are $18 \%$ and $11 \%$ respectively (fig 2 ).

The actual survival of the 134 patients of both groups who had a resection more than 10 years ago is $12(9 \%)$ and of the 279 patients operated on more than five years ago, there are 48 survivors $(17 \cdot 2 \%)$.

Three hundred and sixty-one patients who had a resection survived six months and all the survivors enjoyed early swallowing of at least a soft diet but most patients reported that they could only take small meals at a time, presumably because of the reduced size of the stomach remnant.

If the patients with recurrent cancer are excluded,

Table 7 Resection rates of different surgical series for carcinoma of the oesophagus

\begin{tabular}{|c|c|c|c|c|c|c|}
\hline Author & $\begin{array}{l}\text { Total number } \\
\text { of cases }\end{array}$ & Exploration & Resection & $\begin{array}{l}\text { Operation } \\
\text { rate }(\%)\end{array}$ & $\begin{array}{l}\text { Overall } \\
\text { resection } \\
\text { rate }(\%)\end{array}$ & $\begin{array}{l}\text { Operative } \\
\text { resection } \\
\text { rate }(\%)\end{array}$ \\
\hline Miller C 121961 & 405 & 272 & 198 & 67 & $48 \cdot 8$ & $69 \cdot 5$ \\
\hline Belsey $\mathbf{R}^{5} 1966$ & 198 & 170 & 151 & $85 \cdot 8$ & $76 \cdot 2$ & $88 \cdot 8$ \\
\hline Collis JC $\mathrm{J}^{17} 1971$ & 837 & 450 & 400 & $53 \cdot 7$ & $47 \cdot 7$ & $88 \cdot 8$ \\
\hline Leverment JN ${ }^{18} 1974$ & - & 452 & 381 & - & - & $84 \cdot 3$ \\
\hline Akiyama $H^{14} 1976$ & 270 & - & 140 & - & $51 \cdot 8$ & - \\
\hline McKeown $^{13} 1972-78$ & - & 403 & 372 & - & - & 92 \\
\hline Jackson J11 1979 & 292 & 230 & 216 & $78 \cdot 7$ & 73.9 & 93 \\
\hline Schuchmann $^{21} 1980$ & 214 & $? 57$ & 46 & $26 \cdot 6$ & $21 \cdot 9$ & 80 \\
\hline Present series & 771 & 531 & 449 & $68 \cdot 9$ & $58 \cdot 2$ & 85 \\
\hline
\end{tabular}


only 19 of the 449 resections $(4 \cdot 2 \%)$ had late swallowing difficulties caused by a benign anastomotic stricture bad enough to require dilatation.

By contrast, radiotherapy, which is an alternative treatment for squamous cell tumours, involves a four-week course of 20 daily treatments ${ }^{19}$ and up to $50 \%$ may need oesophageal dilatations. ${ }^{20}$

There is general acceptance that surgery is the best treatment for adenocarcinomas and, while most of these have arisen in the stomach, in the present series $8.8 \%$ of the cases in the high group were adenocarcinomas and were almost certainly all arising in the oesophageal mucosa.

It is difficult to compare the long-term survival between patients having radiotherapy or surgery for squamous cell carcinomas, because in most series where radiotherapy has been the treatment of choice, not all the patients treated would have been suitable for surgery. In the series where surgically acceptable patients were so treated, a figure of between 6 and $20 \%$ five-year survival has been quoted. ${ }^{19}$ In the present series 157 patients with squamous cell cancer were submitted to surgery more than five years ago, 125 of these had a resection and altogether 24 are still alive $(15.4 \%$ five-year survival). If all the patients with squamous cell cancer presenting more than five years ago are considered, then the 24 patients still alive represent an overall $9.4 \%$ survival. Many of those unsuitable for surgery were almost moribund and therefore not suitable for any other attempts at curative treatment.

In conclusion, therefore, we would suggest that this review of the long-term outcome of a large number of patients with malignant oesophageal and high gastric disease supports the present policy of surgical resection.

\section{References}

${ }^{1}$ Ohsawa T. The surgery of the oesophagus. Arch Jpn Chir
$1933 ; 10: 605-95$.

2 Thompson VC. Carcinoma of the oesophagus, resection and oesophagogastrostomy. Br J Surg 1945;32:337-80.

${ }^{3}$ Earlam R, Cunha-Melo JR. Oesophageal squamous cell carcinoma. I A critical review of surgery. Br J Surg 1980; $67: 381-90$.

4 Registrar General. Statistical Review of England and Wales, 1976.

${ }^{5}$ Belsey R, Hiebert CA. An exclusive right thoracic approach for carcinoma of the middle third of the oesophagus. Ann Thorac Surg 1974;18:1-15.

- Allison P, Borrie J. The treatment of malignant obstruction of the cardia. Br J Surg 1949;37:1-21.

7 Berkson J, Gage RP. Calculation of survival rates for cancer. Proc Staff Meetings Mayo Clin 1950;25:270-86.

8 Abel AL. The treatment of cancer of the oesophagus. $\mathrm{Br} J$ Surg 1926;14:131-59.

- McKeown KC. Trends in oesophageal resection for carcinoma. Ann $R$ Coll Surg Engl 1972;51:213-39.

${ }^{10}$ McKeown KC. Total three-stage oesophagectomy for carcinoma of the oesophagus. Br $J$ Surg 1972;63: 259-62.

11 Jackson JW, Cooper DK, Guvendik L, Reece Smith H. Surgical management of malignant tumours of the oesophagus and cardia. Br J Surg 1979;66:98-104.

12 Miller C. Carcinoma of thoracic oesophagus and cardia. Br J Surg 1971;49:507-22.

${ }^{13}$ McKeown KC. Carcinoma of the oesophagus. Ann R Coll Surg Engl 1978;60:301-3.

14 Akiyama H, Hiyama M, Hashimoto C. Resection and reconstruction for carcinoma of the thoracic oesophagus. Br J Surg 1976;63:206-9.

${ }^{15}$ McKeown KC. Surgical treatment of cancer of oesophagus. In: Silber A, ed. Carcinoma of oesophagus. Cape Town: Balema, 1978:378-89.

${ }^{16}$ Nakayama K. In: Tanner NC, Smithers DW, eds. Tumours of the oesophagus. Edinburgh: Livingstone, 1961:248-61.

17 Collis JL. Surgical treatment of carcinoma of the oesophagus and cardia. Br J Surg 1971;58:801-4.

${ }^{18}$ Leverment JN, Milne D. Oesophagogastrectomy in the treatment of malignancy of the thoracic oesophagus and cardia. Br J Surg 1974:61:683-8.

19 Pearson JG. Present status and future potential of radiotherapy in the management of oesophageal cancer. In: Silber W, ed. Carcinoma of the oesophagus. Cape Town: Balema, 1978:334-9.

${ }^{20}$ Earlam R, Cunla-Melo JR. Oesophageal squamous cell carcinoma. II A critical review of radiotherapy. Br J Surg 1980;67:457-61. 